Report Title/Type: $\quad$ Fifteenth Quarterly Technical Progress Report for project entitled "Establishment of an Industry-Driven Consortium Focused on Improving the Production Performance of Domestic Stripper Wells"

Reporting Period: $\quad$ April 1, 2004 - June 30, 2004

Principal Authors: $\quad$ Joel L. Morrison

Report Issue Date: $\quad$ December 23, 2004

Doe Award Number: $\quad$ Grant No. DE-FC26-00NT41025

Submitting Organization:

The Pennsylvania State University

The Energy Institute

C-211 Coal Utilization Laboratory

University Park, Pennsylvania 16802-2323 


\section{DISCLAIMER}

This report was prepared as an account of work sponsored by an agency of the United States Government. Neither the United States Government nor any agency thereof, nor any of their employees, makes any warranty, express or implied, or assumes any legal liability or responsibility for the accuracy, completeness, or usefulness of any information, apparatus, product, or process disclosed, or represents that its use would not infringe privately owned rights. Reference herein to any specific commercial product, process, or service by trade name, trademark, manufacturer, or otherwise does not necessarily constitute or imply its endorsement, recommendation, or favoring by the United States Government or any agency thereof. The views and opinions of authors expressed herein do not necessarily state or reflect those of the United States Government or any agency thereof. 


\section{ABSTRACT}

The Pennsylvania State University, under contract to the U.S. Department of Energy, National Energy Technology Laboratory will establish, promote, and manage a national industry-driven Stripper Well Consortium (SWC) that will be focused on improving the production performance of domestic petroleum and/or natural gas stripper wells. The consortium creates a partnership with the U.S. petroleum and natural gas industries and trade associations, state funding agencies, academia, and the National Energy Technology Laboratory.

This report serves as the fifteenth quarterly technical progress report for the SWC. Key activities for this reporting period include: 1) hosting the SWC spring proposal meeting in Golden Colorado, 2) planning of the upcoming SWC fall technology transfer meetings, and 3) recruiting the SWC base membership. 


\section{TABLE OF CONTENTS}

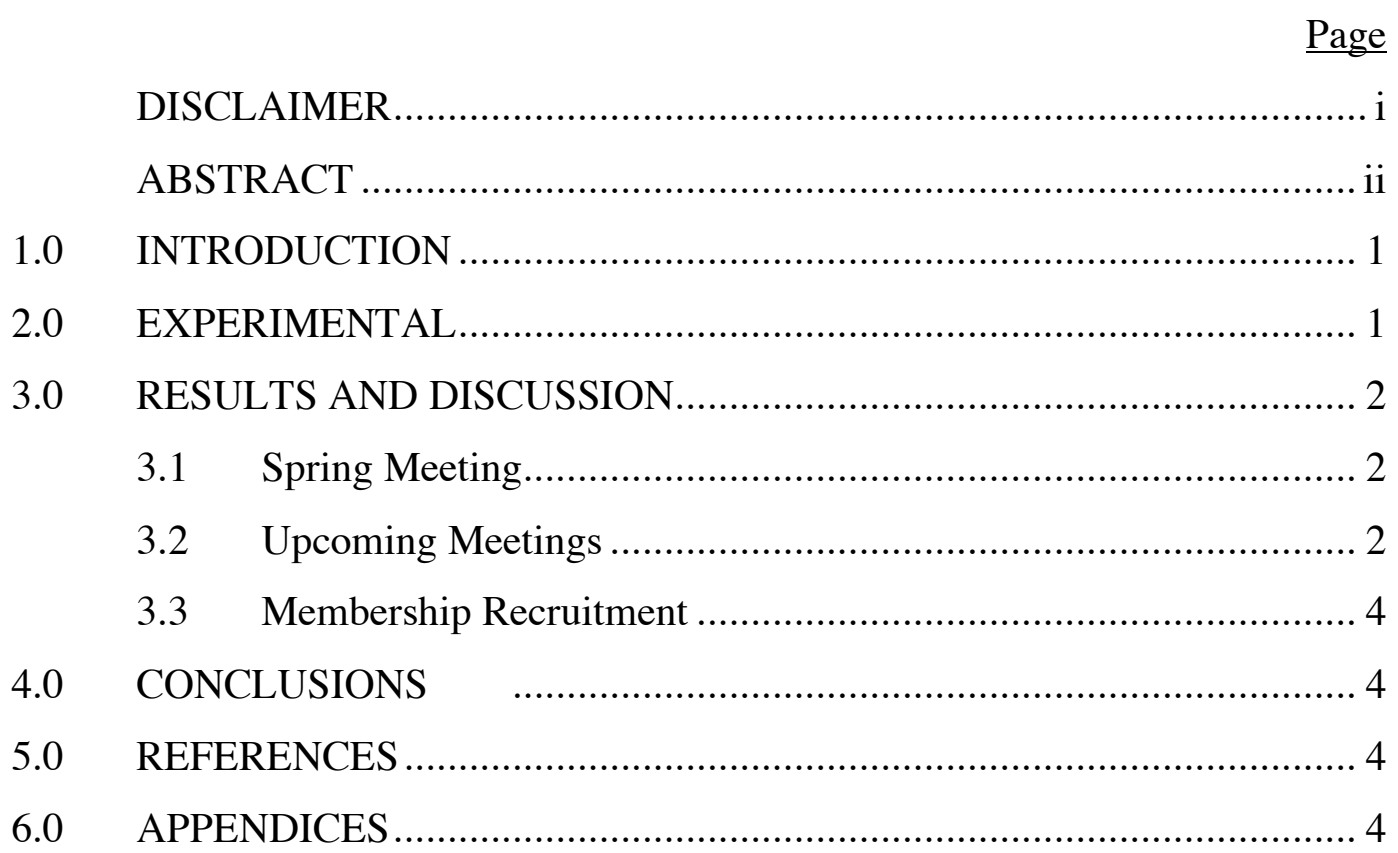




\subsection{INTRODUCTION}

The Pennsylvania State University, under contract to the U.S. Department of Energy (DOE), National Energy Technology Laboratory (NETL), is in the process of establishing an industrydriven stripper well consortium that will be focused on improving the production performance of domestic petroleum and/or natural gas stripper wells. Industry-driven consortia provide a costefficient vehicle for developing, transferring, and deploying new technologies into the private sector. The Stripper Well Consortium (SWC) will create a partnership with the U.S. petroleum and natural gas industries and trade associations, state funding agencies, academia, the National Energy Technology Laboratory, and the National Petroleum Technology Office.

Consortium technology development research will be conducted in the areas of reservoir remediation, wellbore clean up, and surface system optimization. Consortium members elected an Executive Council that will be charged with reviewing projects for consortium co-funding. Proposals must address improving the production performance of stripper wells and must provide significant cost share. The process of having industry develop, review, and select projects for funding will ensure that the consortium conducts research that is relevant and timely to industry. Co-funding of projects using external sources of funding will be sought to ensure that consortium funds are highly leveraged.

\subsection{EXPERIMENTAL}

A description of experimental methods is required by the DOE for all quarterly technical progress reports. In this program, Penn State is responsible for establishing and managing an industry-driven stripper well consortium. Technology development research awards are made on a competitive basis. Therefore, this section is not applicable to the Penn State contracted activities. Technical reports from the individual researchers will be required to contain an experimental discussion section and will be submitted to consortium members and DOE for their review. 


\subsection{RESULTS AND DISCUSSION}

Key activities for this reporting period include: 1) organizing and hosting the SWC spring proposal meeting in Golden Colorado, 2) planning of the upcoming SWC fall technology transfer meetings, and 3) recruiting the SWC base membership.

\subsection{Spring Meeting}

The SWC organized and hosted its spring proposal meeting at the Table Mountain Inn on May 24-25, 2004 in Golden Colorado (agenda on Appendix A). The meeting was dedicated to reviewing the proposals that were submitted to the SWC for co-funding. The Principal Investigators of the proposed projects provided the SWC membership with a 20-minute presentation. Of the 19 proposals received, the Executive Council selected 10 proposals for a total of $\$ 1,036,253$ in funding Table 1 summarizes the projects that were approved for cofunding. Appendix B contains a one page executive summary for these projects. The program breakdown for the approved projects is as follows:

Total Project Value: \$1,737,585

Amount Approved for DOE Co-Funding: \$1,036,253

$\%$ Cost Share: $43 \%$

\subsection{Upcoming Meetings}

The SWC will organize and host two technology meetings in 2004.

Oklahoma City, Oklahoma Workshop. The first technology transfer event will be held in collaboration with the Oklahoma Marginal Well Commission (OMWC) Technology Trade Fair on October 26, 2004 in Oklahoma City, OK. The SWC is a co-sponsor for the event and is organizing 12 exhibit booths to showcase past and present SWC projects.

Northeast Workshop. The second technology transfer workshop will be held in the northeast after the Oklahoma City Trade Fair. The workshop is still in the planning stage. 
TABLE 1: 2004 SWC FUNDED PROPOSALS

\begin{tabular}{|c|c|c|c|c|c|}
\hline \multirow[t]{2}{*}{ Project Title } & \multirow{2}{*}{$\begin{array}{l}\text { Total Project } \\
\text { Value }\end{array}$} & \multicolumn{3}{|c|}{ Funding Source } & \multirow[t]{2}{*}{ Project Participants } \\
\hline & & DOE & NYSERDA & Applicant & \\
\hline $\begin{array}{l}\text { Building and Testing a New Type of Compressor for } \\
\text { Stripper Well Production Application }\end{array}$ & $\$ 428,571$ & $\$ 300,000$ & 0 & $\$ 128,571$ & W\&W Vacuum \\
\hline Hydraulic Fracture Imaging & $\$ 390,000$ & $\$ 110,000$ & $\$ 50,000$ & $\$ 230,000$ & Universal Well Services \\
\hline $\begin{array}{l}\text { Advance Technology for Infill and Recompletion } \\
\text { Candidate Well Selection }\end{array}$ & $\$ 141,064$ & $\$ 98,064$ & 0 & $\$ 43,000$ & Texas A\&M University \\
\hline $\begin{array}{l}\text { Plunger Lift Process Optimization Using a Surface } \\
\text { System for Plunger Generated Acoustic Noise } \\
\text { Detection and Digital Signal Processing for } \\
\text { Wellbore Plunger Location Monitoring }\end{array}$ & $\$ 178,900$ & $\$ 98,900$ & 0 & $\$ 80,000$ & Tubel Technologies \\
\hline $\begin{array}{l}\text { Resolving Discrepancies in Predicting Critical Rate } \\
\text { in Low-Pressure Gas Stripper Wells }\end{array}$ & $\$ 41,500$ & $\$ 29,050$ & 0 & $\$ 12,450$ & Texas Tech \\
\hline A New Look at Foam for Unloading Gas Wells & $\$ 154,964$ & $\$ 101,855$ & 0 & $\$ 53,109$ & Colorado School of Mines \\
\hline $\begin{array}{l}\text { Design, Construction and Evaluation of an } \\
\text { Accurate, Low-Cost Portable Production Tester }\end{array}$ & $\$ 124,300$ & $\$ 84,800$ & 0 & $\$ 39,500$ & Oak Resources \\
\hline $\begin{array}{l}\text { PVT Study of the Interaction of Nitrogen and Crude } \\
\text { Oil, State II }\end{array}$ & $\$ 87,286$ & $\$ 44,584$ & 0 & $\$ 42,702$ & Penn State University \\
\hline $\begin{array}{l}\text { Low Friction Production Tubing for Stripper Gas } \\
\text { Wells }\end{array}$ & $\$ 139,000$ & $\$ 79,000$ & 0 & $\$ 60,000$ & Dyna Coil \\
\hline $\begin{array}{l}\text { Field Testing of the Vortex DXR Retrievable Insert } \\
\text { Tool in Conjunction with Other Lifting Methods }\end{array}$ & $\$ 52,000$ & $\$ 40,000$ & 0 & $\$ 12,000$ & Vortex Flow \\
\hline Summary & $\$ 1,737,585$ & $\$ 986,253$ & $\$ 50,000$ & $\$ 701,332$ & \\
\hline
\end{tabular}




\subsection{Membership Recruitment}

SWC membership recruitment efforts continue through this reporting period. Efforts will be made to increase the membership base during the Technology Trade Fair event in Oklahoma City, Oklahoma.

\subsection{CONCLUSIONS}

Key activities for this reporting period include: 1) hosting the SWC spring proposal meeting in Golden, Colorado, 2) planning and organizing the upcoming SWC fall technology transfer meetings, and 3) recruiting the SWC base membership.

\subsection{REFERENCES}

A listing of referenced materials is required by the DOE for each quarterly technical progress report. This technical progress report for the SWC did not utilize any reference material.

\subsection{APPENDICES}




\section{APPENDIX A: MEETING AGENDA}

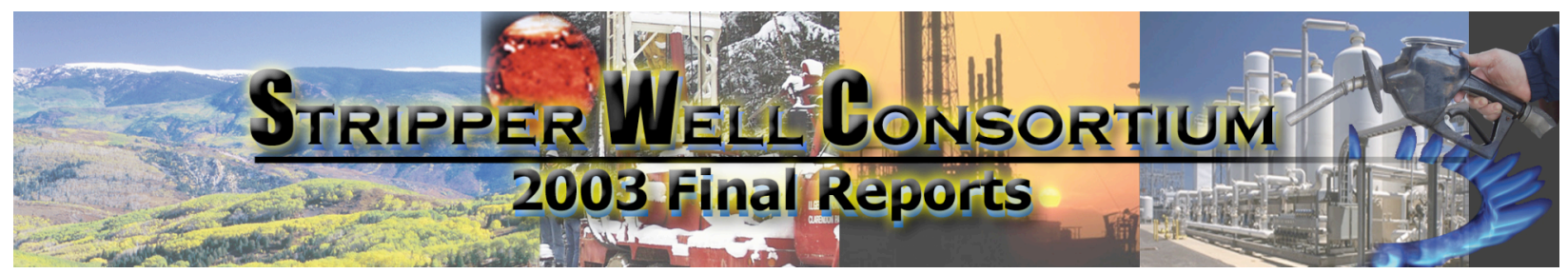

\section{MEETING AGENDA}

Table Mountain Inn

Golden, Colorado

\begin{tabular}{|c|c|}
\hline \multicolumn{2}{|c|}{ May 24, 2004} \\
\hline $7: 30-8: 30$ & Buffet Breakfast (Lakota Lounge and Del Rio Room) \\
\hline $8: 30-9: 00$ & Meeting Registration \\
\hline 9:00 - 9:20 & Welcoming Comments (Arapaho Room) \\
\hline $9: 20-9: 40$ & $\begin{array}{l}\text { New Stimulation Technique for Stripper Wells with High Water Production } \\
\text { Presenter: Louisiana State University }\end{array}$ \\
\hline $9: 40-10: 00$ & $\begin{array}{l}\text { Oil Viscosity Reduction Through Sonication Stimulation and Chemical } \\
\text { Additives, East Gilbertown Field, West-Central Alabama } \\
\text { Presenter: TechSavants }\end{array}$ \\
\hline $10: 00-10: 20$ & $\begin{array}{l}\text { Building and Testing a New Type of Compressor for Stripper Well } \\
\text { Production Application } \\
\text { Presenter: W\&W Vacuum \& Compressions Inc. }\end{array}$ \\
\hline $10: 20-10: 40$ & Break \\
\hline $10: 40-11: 00$ & $\begin{array}{l}\text { A Study to Optimize Stripper Well Production Monitoring and Measurement } \\
\text { Presenter: James Engineering }\end{array}$ \\
\hline $11: 00-11: 20$ & $\begin{array}{l}\text { Retrofit Three Stripper Wells with Open Hole Completions to Accept GOAL } \\
\text { PetroPumps to Enhance Performance } \\
\text { Presenter: Brandywine Energy Development Co. (BEDCO) }\end{array}$ \\
\hline $11: 20-11: 40$ & $\begin{array}{l}\text { Linking GEMINI Geo-Engineering Web Software to Public Domain Databases } \\
\text { and Enhancement of Software Modules to Address Marginal and Low BTU } \\
\text { Gas Production } \\
\text { Presenter: University of Kansas }\end{array}$ \\
\hline $11: 40-12: 00$ & $\begin{array}{l}\text { Hydraulic Fracture Imaging } \\
\text { Presenter: Universal Well Services }\end{array}$ \\
\hline $12: 00-1: 00$ & SWC Luncheon (Lakota Lounge and Del Rio) \\
\hline
\end{tabular}




\begin{tabular}{|c|c|}
\hline $1: 00-1: 20$ & $\begin{array}{l}\text { Casing Swabbing Project in Osage County, Oklahoma } \\
\text { Presenter: Hominy Creek Energy Company }\end{array}$ \\
\hline $1: 20-1: 40$ & $\begin{array}{l}\text { Advance Technology for Infill and Recompletion Candidate Well Selection } \\
\text { Presenter: Texas A\&M University }\end{array}$ \\
\hline $1: 40-2: 00$ & $\begin{array}{l}\text { Demonstration of Hydrojet Slotting on Three Important Types of Wells } \\
\text { Presenter: American Hydroslotter Corporation }\end{array}$ \\
\hline $2: 00-2: 20$ & $\begin{array}{l}\text { Plunger Lift Process Optimization Using a Surface System for Plunger } \\
\text { Generated Acoustic Noise Detection and Digital Signal Processing for } \\
\text { Wellbore Plunger Location Monitoring } \\
\text { Presenter: Tubel Technologies }\end{array}$ \\
\hline $2: 20-2: 40$ & $\begin{array}{l}\text { Novel Approach to Identifying the Most Cost Effective Fluid Removal } \\
\text { Process in Stripper Gas Wells with Applications in New York State } \\
\text { Presenter: Schlumberger-Holditch }\end{array}$ \\
\hline $2: 40-3: 00$ & $\begin{array}{l}\text { Resolving Discrepancies in Predicting Critical Rate in Low-Pressure Gas } \\
\text { Stripper Wells } \\
\text { Presenter: Texas Tech University }\end{array}$ \\
\hline 3:00-3:30 & Break \\
\hline $3: 30-5: 30$ & Excursion to Colorado School of Mines \\
\hline $5: 30-7: 00$ & SWC Reception (Kokopelli Room) \\
\hline
\end{tabular}




\begin{tabular}{|c|c|}
\hline \multicolumn{2}{|r|}{ May 25, 2004} \\
\hline $8: 00-9: 00$ & Breakfast Buffet (Lakota Lounge and Del Rio Room) \\
\hline $9: 00-9: 20$ & $\begin{array}{l}\text { Rocky Mountain Oilfield Testing Center (RMOTC): Taking New Technology } \\
\text { from Concept to Demonstration } \\
\text { Presenter: Tom Anderson, Business Development Manager }\end{array}$ \\
\hline $9: 20-9: 40$ & $\begin{array}{l}\text { Redesign, Development and Upgrade to Hydroslotter Technology } \\
\text { Presenter: American Hydroslotter Corporation }\end{array}$ \\
\hline $9: 40-10: 00$ & $\begin{array}{l}\text { A New Look at Foam for Unloading Gas Wells } \\
\text { Presenter: Colorado School of Mines }\end{array}$ \\
\hline $10: 00-10: 20$ & $\begin{array}{l}\text { Design, Construction and Evaluation of an Accurate, Low-Cost Portable } \\
\text { Production Tester } \\
\text { Presenter: Oak Resources }\end{array}$ \\
\hline $10: 20-10: 40$ & Break \\
\hline $10: 40-11: 00$ & $\begin{array}{l}\text { PVT Study of the Interaction of Nitrogen and Crude Oil, Stage II } \\
\text { Presenter: Penn State University }\end{array}$ \\
\hline $11: 00-11: 20$ & $\begin{array}{l}\text { Low Friction Production Tubing for Stripper Gas Wells } \\
\text { Presenter: Dynacoil }\end{array}$ \\
\hline $11: 20-11: 40$ & $\begin{array}{l}\text { Field Testing of the Vortex DXR Retrievable Insert Tool in Conjunction with } \\
\text { Other Lifting Methods } \\
\text { Presenter: Vortex Flow }\end{array}$ \\
\hline $11: 40-11: 45$ & Closing Comments / Meeting Adjourned \\
\hline $12: 00-4: 00$ & Executive Council Meeting (Del Rio Room) \\
\hline
\end{tabular}




\title{
APPENDIX B: EXECUTIVE SUMMARY
}

\section{BUILDING AND TESTING A NEW TYPE OF COMPRESSOR FOR STRIPPER WELL PRODUCTION APPLICATION}

\author{
Lead Organization: \\ Principal Investigator: \\ Total Project Cost: \\ Level of Funding:
}

\author{
W \& W Vacuum \\ Paul Weatherbee \\ (325) 695-4637,wildcattr@aol.com \\ $\$ 428,571$ \\ $\$ 300,000$
}

\section{EXECUTIVE SUMMARY}

A novel variable capacity compressor has been developed to solve compressor problems encountered in low deliverability gas production operations. The design is the result of 10 years' research by Paul Weatherbee and associates. In Phase I, we have built and are testing two prototypes. In Phase II, we are proposing to optimize the design using structural and thermal Finite Element Analysis along with Computational Fluid Dynamics, and by performing bench and field testing using multi variate design of experiments and analysis. It is anticipated that Phase II will result in an efficient, reliable, low-cost design that will show significant advantages in the field.

The Weatherbee Positive Displacement Compressor/Vacuum Pump, a patented device, has the largest volume displacement to size ratio of any device in the world. The geometry of the spherical design provides the largest internal volume to surface area ratio possible so that with each 360-degree revolution, the Weatherbee Pump displaces almost all of its internal volume.

Another feature unique to the Weatherbee Pump is a capacity control mechanism. This volume control feature works like a throttle on an engine; set on high it can easily handle high volumes, and by throttling back the mechanism, volumes are reduced - thereby saving on energy usage and operating costs. With most compressor devices, volume or output capacity is limited to increasing or decreasing the rotation rate of the drive shaft. This capacity control mechanism allows the flow rate of the device to be varied to meet increased or decreased demands without changing the rotation rate of the drive shaft. The device uses only the energy necessary to compress the amount of gas the well is actually producing. This capacity control feature is a major selling point for a majority of applications. The ease of sizing makes one pump appropriate for various flow requirements. This feature will be particularly beneficial to applications where compression requirements fluctuate or where volume can only be estimated and may vary drastically over time, as in gas well compression.

The Weatherbee Pump functions equally well whether rotating clockwise or counter-clockwise and is controlled by the direction in which the input shaft is rotating. Additionally, the device can be mounted in any position without normal operations being affected. The versatility of this pump is particularly useful when the unit is being used as a component part of a system where pump orientation or shaft rotation is predetermined or limited by other components.

When compared to existing products of similar output capacities, the Weatherbee Pump provides the following advantages: (1) substantially reduced size and weight; (2) versatility of the volume control mechanism; (3) reduced energy requirements; (4) a ported device that requires no valves (5) lower maintenance and operating costs; (6) pump can be operated with input shaft turning either clockwise or counter-clockwise; (7) the direction of flow can be completely reversed in the device without disconnecting the pump or changing rotational direction of input shaft; and (8) pump can perform a dual function; i.e., simultaneous motor and pump/compressor. 


\section{HYDRAULIC FRACTURE IMAGING}

\section{Lead Organization: Key Contact:}

Total Project Cost: Level of Funding:

\author{
Universal Well Services \\ Roger Willis \\ (814)337-1983,rwillis@univwell.com \\ $\$ 390,000$ \\ $\$ 110,000$
}

This proposal involves bringing a technology into the Appalachian Basin to image hydraulic fractures as they are being created. It also will develop the evaluation and engineering techniques to apply the information gained to the design of hydraulic fractures for marginal wells in the Basin. At present there is no direct evidence which proves the actual fracture dimension and geometry for any of the many regional stripper well reservoirs that are stimulated by hydraulic fracturing.

Fracture imaging technologies have been used in more prolific areas of the world but have not been applied in this region due to several factors. The engineering evaluations to plan for the use of the process are a tall hurdle for the economic realities that control technology application on the stripper wells that so badly need the data that can be gained. The equipment and engineering support is located in the Western US and is prohibitively expensive to mobilize and utilize in this area.

The goal of this project is to use this available technology to image hydraulic fractures and demonstrate how the engineering process is done so that it can be applied to other marginal stripper wells in the Basin. Understanding the geometry of created hydraulic fractures will help operators answer many questions that affect their every day economics and profitability including: well spacing and locating for maximum resource recovery, fracture design and application parameters such as job size and cost, determining if all of the potential pay zones have been effectively treated by the fracture stimulation treatment they are utilizing. This could have major implications for the many stripper wells in the basin if it is found that potential exists for recompletion of unstimulated intervals.

Many operators utilize computer simulation models to help design their fracture stimulations. Unfortunately there is no data available to calibrate the models and validate their recommendations. One of the first contributions from this project will be the calibration of regional fracture models with actual data.

The project will involve preliminary engineering reviews and design as well as the actual imaging of hydraulic fractures with the appropriate technology after it has been determined which method will do the best job. It is anticipated that from two to four wells will be imaged. 


\title{
ADVANCED TECHNOLOGY FOR INFILL AND RECOMPLETION CANDIDATE WELL SELECTION
}

\author{
Lead Organization: \\ Key Contact: \\ Texas A\&M University \\ Duane McVay \\ (979) 862-8466, mcvay@ spindletop.tamu.edu \\ $\$ 141,064$ \\ Total Project Cost: \\ $\$ 98,064$
}

Quantifying the remaining potential in marginal oil and gas fields is difficult due to reservoir heterogeneity, variable well completion and stimulation practices, and sparse databases that are inadequate for reservoir characterization. In lieu of time-consuming and expensive conventional reservoir studies, statistical analyses of production data have been used to aid in reservoir characterization and to select locations for infill drilling and wells for recompletion and restimulation. In our previous project for the Stripper Well Consortium, we investigated the use of a simulationbased regression approach, with promising results, as an alternative to statistical techniques for rapid assessment of infill potential in stripper well fields.

In this proposal, researchers from Texas A\&M University, Quicksilver Resources and MGV Energy seek to extend, refine and validate the simulation-based regression approach. The technology will be applied in the Viking Formation in the Western Canada Sedimentary Basin to identify areas for recompletion and infill drilling and to determine potential production increases. The Viking formation was selected for this study because of its long gas production history with a significant fraction of the wells now producing at stripper-gas rates, availability of data, and the existence of numerous analogous reservoirs for technology transfer in Canada and the U.S. Thus, Viking reservoirs are excellent candidates for testing rapid assessment methods that can be transferred to other stripper gas fields.

We anticipate that key deliverables from this project will be advanced technology and a fit-for-purpose software application for assessment of infill drilling and recompletion potential in stripper gas fields. Key characteristics of the technology will be rapid and cost-efficient assessment, primary reliance on widely available production data, ease of transition to more detailed interpretations, and importantly, increased accuracy over statistical methods. The advanced technology and software developed and used in this project will be valuable reservoir development and management tools that can be widely applied by independent operators to help make business decisions regarding redevelopment potential in stripper gas fields. 


\title{
PLUNGER LIFT PROCESS OPTIMIZATION USING A SURFACE SYSTEM FOR PLUNGER GENERATED ACOUSTIC NOISE DETECTION AND DIGITAL SIGNAL PROCESSING FOR WELLBORE PLUNGER LOCATION MONITORING
}

\author{
Lead Organization: \\ Key Contact: \\ Tubel Technologies \\ Paulo Tubel \\ (281) 364-6030, paul.tubel@ tubeltechnologies.com \\ Total Project Cost: \\ $\$ 178,900$ \\ Level of Funding: \\ $\$ 98,900$
}

The hydrocarbon producers today are faced with significant challenges to maintain wells operational and production cost effectiveness due to large changes in electricity rates in different parts of the US, volatility of oil and gas prices and unexpected requirements for intervention in the wells. Optimization of the processes required to produce hydrocarbons constitutes an on going concern in the oil and gas industry. The goal of this project is to develop a low cost surface system to monitor the plunger travel in a well and when it hits the springs in the lower section of the well. The purpose of monitoring the plunger location is to assure that the maximum amount of liquids will be lift every time the plunger is brought to the surface. The surface system will be based on an existing commercial low end system used to process data from a downhole wireless gauge system developed by Tubel Technologies in conjunction with the Stripper Well Consortium for low end wells. This new system will be able to optimize plunger lifting operation and to lower lifting costs and increase the pump reliability. The project will acquire and map the noise generated by the plunger in the well as it travels in and out of the well in an attempt to determine when the plunger hits the springs in the well. This project will research, develop and test a low cost, high reliability, real time system to determine when the plunger hits the springs inside the wellbore to optimize the lifting process by reducing shut in time, and ensuring adequate fluid removal from the well bore. The surface system will be divided into 2 sections: A wellhead acoustic to electrical converter module and a low cost portable system with advanced real time digital signal processor and interface to a pump controller will command the pump controller to start the unloading process. 
RESOLVING DISCREPANCIES IN PREDICTING CRITICAL RATE IN LOW-PRESSURE GAS STRIPPER WELLS

\author{
Lead Organization: \\ Texas Tech University \\ Key Contact: \\ Teddy Oetama \\ (806) 742-3573, teddy.oetama@ coe.ttu.edu \\ Total Project Cost: \\ $\$ 41,500$ \\ Level of Funding: \\ $\$ 29,050$
}

Natural gas stripper wells generally produce with low rates and low pressures from depleted reservoirs. The lowrate, low-pressure conditions in wellbore cause liquids to easily drop out from producing gas stream, and eventually result in liquid holding in the wellbore. When the liquid holding happens, gas production is significantly reduced as such that the wells may no longer produce with a commercial rate. Turner et.al.2 defined a critical rate, which is the minimum rate required to keep liquids in the gas stream. They developed a correlation between critical velocity and wellhead pressure. Unfortunately, their correlation is only based on wellhead pressures (700 psia or greater), therefore it may not be applicable to stripper wells that usually have less than $100 \mathrm{psia}$ at wellhead. Subsequent work by Coleman et.al.3 and Kees et.al.4 do not very well agree with Turner et.al.'s, particularly for the critical rates at low pressures.

This proposal is to experimentally determine the critical rate at low pressures and evaluate discrepancy in the previous work. The main objective is to improve/develop critical rate versus wellhead pressure correlations, specifically intended for use in low-pressure gas stripper wells. Texas Tech Petroleum Engineering department has built a test facility that can be used for the propose experiment. Using this facility flow rate and pressure data will be collected and liquid droplet will be observed. All work in this proposal are called as Phase I. In the next Phase II we will test all correlations by conducting experiments in a 4,100-foot "Red Raider No.1" well, which is a test well for experimental purposes and located approximately 7 miles east of Texas Tech campus in Lubbock.

It is crucial to accurately estimate the critical rate in low-pressure stripper wells from experimentally developed correlations, so gas operators can diagnose liquid loading problems and plan appropriately for handling the problems, such as putting gas wells on compressor, placing a down-hole heater in the wellbore, performing wellbore cleanup, etc. Treat the symptom early avoid the problem later. 


\section{A NEW LOOK AT FOAM FOR UNLOADING GAS WELLS}

\section{Lead Organization: Key Contact:}

Total Project Cost: Level of Funding:
Colorado School of Mines

Richard L. Christiansen

(303) 273-3965,rchristi@mines.edu

$\$ 154,964$

$\$ 101,855$

Objective. Compare pressure drop and flow rate data to correlations for foam flow in vertical tubing. Develop a new correlation for foam flow.

Motivation. Removal of water and hydrocarbon liquids from gas wells is increasingly recognized as an important topic for mature gas reservoirs. Foam, produced by surfactants, is one of the leading methods for unloading gas wells. The surfactants are delivered to the well as soap sticks or as liquid injected into the casing-tubing annulus or down a capillary line to the producing interval. Although the relation between pressure drop and flow rate has been studied previously, there are questions about the most appropriate method for estimating pressure profiles. The objective of this research is to re-visit the relationship and determine if existing correlations are adequate.

Specific Directions. The three tasks proposed below describe the specific directions for this foam study. A fourth task of general interest for technology transfer and a fifth task that completes a previous SWC project are also included.

1. Pressure Drop and Flow Rate. Use the existing flow loop in the High Bay Lab as CSM to experimentally study this relationship for conditions typical of stripper gas wells.

2. Existing Correlations. Compare existing correlations with results of Task 1.

3. New Correlation. Modify the Duns-Ros correlation to fit the foam flow data of Task 1 .

4. Liquid-Lifting Short Course. Organize a one-day short course on lifting liquids from gas wells using the CSM Flow Loop for hands-on demonstrations.

5. Final Development and Testing of Mist Device. Complete the development of a mist generator suitable for testing in a shallow gas well. 


\section{DESIGN, CONSTRUCTION AND EVALUATION OF AN ACCURATE, LOW-COST, PORTABLE PRODUCTION WELL TESTER}

\section{Lead Organization: \\ Key Contact:}

Total Project Cost: Level of Funding:

\author{
Oak Resources \\ Kenneth Oglesby \\ (918) 627-8012, OAKK@aol.com \\ $\$ 124,300$ \\ $\$ 84,800$
}

Secondary Recovery methods, primarily waterflooding, provides approximately $50 \%$ of the oil production in Oklahoma. Much of this secondary production is in the northeast and the south areas of Oklahoma. It is also a significant amount in other states. These operations handle large volumes of water, small volumes of oil and, sometimes, natural gas. In addition, the Hunton, Bartlesville and Arbuckle formations also produce large amounts of water with smaller amounts of oil and gas under primary production. Oak has and does operate such wells in southern Oklahoma. Accurate testing of such wells is important to determine reserves, the economics of continued operations and to evaluate projects (recompletion, gel polymers, horizontal laterals, other actions) to improve oil and gas production and/or reduce water production. There is no substitute for good accurate data on which to base these decisions.

Such production well testing is currently done by a centralized separation and metering stations (utilizing standard oilfield equipment or expensive electronic testing equipment) or by portable testers (standard oilfield equipment or expensive electronic testing equipment). Centralized systems require extra lines to be installed and maintained over their entire lives. This results in increased cost and risks. Portable systems allow testing at the individual well or wells and does not require additional lines to be installed and maintained. Low cost portable testers $(\$ 10,000)$ are not accurate enough, due to sampling frequency and gas interference. High cost units are about $\$ 50,000+($ after prototyping and testing the cost can be up to $\$ 100,000)$ which is out of the economic reach of most independent operators. Also many wells do not have electricity available on site. Thus operators must settle for low cost instead of accuracy.

Oak proposes to research all possible testing configurations and equipment, then design, construct and test the final selected configuration of a portable electronic production well tester that is accurate and with the potential of lowcost (in the $\$ 20,000$ price range including testing) in second generation units. To perform this task and meet this goal, Oak will work with Dr. Praviz Mehdizadeh of Petroleum Technology, Inc. from Phoenix, Arizona, a renown expert in multiphase measurement and pumping. This unit will be field tested in a minimum of 30 southern Oklahoma wells, including Oak's wells and other wells in which Oak has access. In the testing period, it will be compared to the current low-cost portable well testing equipment. 


\section{PVT STUDY OF THE INTERACTION OF NITROGEN AND CRUDE OIL, STAGE II}

\section{Lead Organization: Key Contact:}

Total Project Cost: Level of Funding:
The Pennsylvania University

Robert W. Watson

(814)865-0531,rww1@psu.edu

$\$ 87,286$

$\$ 44,584$

A nitrogen huff and puff process has been utilized to stimulate oil production in the Big Andy field located in eastern Kentucky. This nitrogen stimulation project has been ongoing for over 5 years, in which a four fold increase in oil production has been achieved. Nitrogen is generated on site, at an economic cost of 1 dollar per MCF by utilizing a membrane separation technology. Approximate gas consumption has been 1.3 MCF of nitrogen per barrel of oil produced. The nitrogen is being generated onsite and contains about 5 percent oxygen by volume. Given the fact that a significant increase in oil production has been observed, the question becomes what impact does the oxygen have on the crude oil. Is this process viable in the long run, and what is the extent of the nitrogenoxygen application to other stripper wells?

The objective of a currently funded stripper well project has been to develop an understanding of the phase behavior of nitrogen-oxygen gases in the presence of hydrocarbons. In order to meet this objective, a PVT system was fabricated in order to measure the impact on the physical properties of the crude oil. System validation tests have been completed with propane, methane/propane and propane/ethane mixtures at different temperatures. Pressure versus specific volume data has been generated and compares well with published charts in the literature.

Experiments have begun with samples of crude oil from the Big Andy field in Kentucky. Nitrogen gas has been bubbled through a known volume of oil in the PVT cell apparatus. Gas samples are periodically taken from the PVT cell exhaust gas, and are analyzed in a Gas Chromatograph. These analyses show that light hydrocarbons are being stripped from the crude as nitrogen is bubbled through continuously with time.

Having established a laboratory PVT cell protocol, the next phase will be the completion of data collection from the Big Andy field and the implementation of a zero-dimensional model to optimize the recovery process. 


\section{LOW FRICTION TUBING FOR GAS WELL DE-LIQUIFICATION}

\section{Lead Organization: Key Contact:}

\section{Total Project Cost: Level of Funding:}

\author{
Dyna Coil \\ David R. Smith \\ (903) 984-1039 \\ david.smith@dynacoil.com \\ $\$ 139,000$ \\ $\$ 79,000$
}

The proposed project will develop economical methods to deploy low coefficient of friction production tubing configurations into stripper gas wells. The principal objective is to more efficiently de-liquefy stripper gas wells by developing well site deployment methods compatible with lower coefficient of friction production tubing configurations. A second objective is to investigate and select low cost production tubing materials applicable to stripper gas wells cost structure to be used in the project. Enhanced gas production will be achieved by reducing the minimum reservoir pressure required to keep a given tubular geometry above its Minimum Critical Velocity, MCV, to transport liquids out of the well. The technology developed will contribute to increase reserve recovery for stripper gas wells.

The investigators will study the down hole temperatures and depths of most stripper gas wells in the USA. They will also investigate the various casing sizes required for production tubing to be deployed into. They will further investigate the material properties such as creep, toughness, down hole environment stress crack resistance, tensile strength, burst, collapse, and coefficient of friction of a variety of materials that can be constructed economically in the common sizes required for stripper wells. They will then select the tubing materials, diameters, and lengths that will meet the largest number of wells most economically.

The investigators will then design deployment equipment and methods to run the selected tube into wells. They will focus on developing equipment that allows for the tubular to be deployed at economical rates for stripper wells, avoiding the cost of large work over rigs, or large coiled tubing methods currently used in the industry.

Previous investigators over the last 10 years have attempted to deploy carbon wound tubes, and other plastic reinforced tubes, to reduce friction, decrease corrosion, and scale common in carbon steel tubulars. They focused on ultra-high strength tubulars and deployment methods that were largely for high pressure gas and oil wells. The investigators for this project will not focus on high differential pressure tubulars to be run in high pressure wells, as stripper wells do not use tubing for pressure containment but largely for fluid velocity increases.

The principal objective of this project is then to increase the recovery of gas reserves by developing a system of deployment equipment appropriate for low cost, and low coefficient of friction tubular materials. A second objective is to design the system such that it can be deployed into stripper gas wells at an exceeding lower cost than rig intervention methods for carbons steel production tubing. A further objective is to immediately increase the gas production from stripper wells by increasing the amount of liquids they can produce to surface thereby allowing more gas to be produced from the reservoir. 


\section{FIELD TESTING OF THE VORTEX DXR RETRIEVABLE INSERT TOOL IN CONJUNCTION WITH OTHER LIFTING METHODS}

\section{Lead Organization: Key Contact:}

\section{Total Project Cost: Level of Funding:}

\author{
Vortex Flow \\ Tom Smith \\ (720) 227-0350 \\ tsmith@vortexflowllc.com \\ $\$ 52,000$ \\ $\$ 40,000$
}

In the spring of 2002, Vortex Flow, LLC was awarded a grant by the SWC to research, design and make lab tests of a downhole tool using the patented Vortex Flow technology. The technology takes a disorganized single or multiphase flow and transforms it to a spiral flow with an associated boundary layer that runs along the inside wall of the pipe. The vortex flow that is created by the technology reduces friction that causes pressure drops as fluids (gas or liquids) flow through a pipe. The object of applying the technology in a downhole setting is the reduction of pressure drops in a tubing string. Initial tests have shown that the tool has the potential to reduce pressure drops in tubing strings thus increasing production of both gas and oil in low flowrate stripper wells.

Several tool designs were manufactured and later tested at Texas A\&M University as part of a Master's Thesis by a graduate student. Initial test results indicated that the final tool design reduced the pressure drop up the tubing string and reduced the required gas flow required to lift liquids up the wellbore. This testing was also the source for an SPE paper that was presented at the October '03 Annual SPE Conference in Denver.

In the spring of 2003, Vortex Flow, LLC was awarded a grant to field test the Vortex DX downhole tools with Marathon Oil. The field test results were very encouraging and were the basis for a recent World Oil case study article in the May 2004 issue.

However, as well as the DX tools performed the application of the technology requires the operator to 'pull tubing to deploy. This requirement greatly increased the cost of a DX project. As a result, Vortex Flow developed a new model of the downhole tool (DXR) that is able to be deployed via slickline through the tubing string and set downhole in a collar stop. Vortex Flow has been installing these tools with customers since January of 2004. The DXR tools dramatically reduce the cost to deploy the Vortex tools and can enable the installation to be economically viable for many more lower-rate wells.

Based on field data to date, it appears that the DXR tools can indeed enable a well to 'flow' even with only $75 \%$ of the required critical gas rate. However, many stripper gas wells are further below that critical gas rate level. Vortex believes that the DXR tools could still provide significant economic benefit to such lower rate wells when deployed in tandem with other low cost liquid lifting methods such as surfactants, plunger lifts and velocity strings.

Vortex is submitting this grant proposal for 2004 to determine the extent that a DXR tool can enhance a well's performance in conjunction with certain other liquid lifting techniques. We believe that by combining a DXR tool with other lower cost lifting methods that the combined solution will further lower the critical gas rate required to keep a well flowing to as low as $40 \%$ of the critical gas rate and could replace a larger number of more expensive traditional lifting methods such as mechanical pumping units. 